pared with only 87 (34\%) of 442 of those receiving a memorandum outlining vaccine indications. Questionnaire results indicated that only $32 \%$ had ever been previously immunized against influenza, although $70 \%$ stated that they had worked despite having influenzalike symptoms.

The authors concluded that the best way to achieve a high rate of immunization of house staff and medical students is to offer the vaccine during conferences and in clinics.

FROM: Ohrt CK, McKinney P. Achieving compliance with influenza immunization of medical house staff and students. JAMA.1992;267:1377-1380.

\section{Outbreak of Herpes Simplex I Virus in ICU}

A cluster of four cases of herpes simplex virus type 1 (HSV-1) was identified in a medical intensive care unit of a university teaching hospital, leading to an epidemiologic investigation that documented horizontal transmission of the virus.

Restriction endonuclease analysis of DNA linked 2 healthcare workers and a family member to the index patient, a 64-year-old man with lymphoma being treated for perioral HSV-1 infection. The patient was receiving high-dose steroid therapy for bleomycin lung toxicity. HSV-1 keratoconjunctivitis developed in the physician one week after performing an emergency intubation and bronchoscopy on the patient. The physician, who wore contact lenses, was not wearing protective goggles and gloves. The patient's primary care nurse developed herpetic whitlow within one week of caring for the patient. The patient's grandson, who had no previous history of HSV1 infection, developed an oral lesion 5 days after visiting his grandfather and was reported to have kissed him on the face.

Infection control policies in this hospital require barrier precautions and handwashing after contact with patients with herpetic lesions. Gloves and protective eyewear are also required when there is any potential for contact with secretions. The authors concluded that this cluster of HSV-1 cases probably occurred because of poor compliance with infection control or because of ineffective protocols. The authors recommend that implementation of mucous membrane barrier precautions, such as the use of goggles during invasive procedures like bronchoscopy and the use of gloves, in cases of HSV-1 respiratory infections such as pneumonia or tracheobronchitis, to prevent transmission of infection with this virus.

from: Perl TM, Haugen TH, Pfaller MA, et al. Transmission of herpes simplex virus type-1 infection in an intensive care unit. Ann Intern Med. 1992;117:584-586.

\section{NIOSH to Expand Research on Workplace Transmission of Infectious Diseases}

The National Institute of Occupational Safety and Health (NIOSH), part of the Centers for Disease Control and Prevention, will expand several research projects in 1993 on work-related transmission of infectious disease. Brian Hardin, NIOSH's assistant administrator, announced at a recent National Safety Congress that the institute will conduct research programs on workplace risk reduction, training, and health hazard investigation.

Research into identifying strategies to reduce risk of HIV infection, including prevention of needlestick injuries, will continue to be among the priorities for NIOSH because needlesticks are the primary source of transmission of HIV in the healthcare setting.

Hardin also reported that NIOSH will conduct research regarding the issue of whether aerosols released during surgical manipulation of tissue and bone could expose surgeons and others to the virus, a widely debated topic. One specific project to begin in 1993 will include videotaping operations while other researchers simultaneously monitor airborne particulate levels. 